\title{
PRODUÇÃO ARTÍSTICA DIGITAL COLABORATIVA E APRENDIZAGEM CURRICULAR NO PROJETO PROEJA-TRANSIARTE
}

\author{
L. F. TELES
}

Universidade de Brasilia

teleslucio@gmail.com

Artigo submetido em fevereiro/2014 e aceito em março/2014

\section{RESUMO}

O projeto PROEJA-Transiarte desenvolve práticas de inovação pedagógicas na Educação de Jovens e Adultos (EJA) e Educação Profissional (EP) introduzindo novas linguagens artísticas digitais no currículo. O projeto autase no trabalho colaborativo, na aprendizagem e produção com as novas mídias, pensadas a partir de expressões artísticas já existentes e vivenciadas e que são reconfiguradas. Esse processo envolve a discussão e reelaboração constante do objeto artístico a ser compartilhado no ciberespaço e a este processo demos o nome de transiarte ou arte de transição. A metodologia utilizada é a pesquisa-ação (Barbier, 2004), que permite a modificação da realidade em conjunto com os participantes, a partir da inclusão digital e social destes. O processo de criação artística colaborativa se nutre da experiência dos participantes, na reinterpretação do vivenciado a partir da subjetividade e preferência artística dos participantes que desenvolvem sua própria identidade local e no ciberespaço. O projeto propõe-se explorar a transiarte na aprendizagem curricular como eixo que integre a Educação de Jovens e Adultos a Educação Profissional abrindo opções de profissionalização e qualificação orientado às tecnologias da informação e comunicação.

PALAVRAS-CHAVE: PROEJA, transiarte, ciberarte, pesquisa-ação, EJA e EP.

\section{COLLABORATIVE DIGITAL ART PRODUCTION AND CURRICULUM LEARNING IN THE PROEJA-TRANSIARTE PROJECT}

\begin{abstract}
Practices of pedagogical innnovations in Adult and Professional Education are carried out in the PROEJATransiarte Project, introducing the use of new artistic digital media in the curriculum. The Project is based in collaborative work, in the production and the support of learning with new media. The work is done from existing artistic expressions of participants which are then reconfigured for the cyberspace. This process consists in the discussion and constant re-elaboration of the artistic object to be shared in cyberspace, which is named art of transition or transiart for short. The research
\end{abstract}

methodology is the action-research (Barbier, 2004), which allows for the transformation of reality by participants, leading to their social and digital inclusion. The process of colaborative artistic creation is nurtured by the experience of participants in the reinterpretation of their lives. Participants develop their own subjectivity and local and global identities in cyberspace. The Project is oriented towards the exploration of transiart in curriculum learning as an axis that integrates Adult Learning, opening possibilities for professionalization in technologies of information and communication. 


\section{INTRODUÇÃO}

A educação de jovens e adultos - EJA é hoje um dos maiores desafios que o país tem pela frente. São 56 milhões de brasileiros que ainda não terminaram o ensino fundamental ou ensino médio. Somente no Grande Distrito Federal - GDF, são 628.000 jovens e adultos que não completaram o ensino fundamental (CASTIONI,2012, p. 57).

Para capturar melhor o interesse e atenção do jovem e do adulto que desejam terminar o ensino fundamental ou médio tenta-se a ligação de EJA com o ensino profissional. Desta maneira ao terminar o ensino fundamental ou médio, o estudante EJA tem também uma profissão com certificado de conclusão. São portanto varias iniciativas governamentais que estão sendo levadas a cabo nesta direção (LEMES, 2012, p. 88).

Uma destas iniciativas é o Projeto PROEJA-Transiarte que se leva a cabo no Centro de Ensino Médio 03 em Ceilândia em parceria com a Escola Técnica de Ceilândia - ETC (LEMES, 2012). 0 projeto busca ensinar o uso de tecnologias digitais na produção artística de estudantes PROEJA como motivador, e integrar esta produção digital com a aprendizagem de temas curriculares. $O$ eixo integrador deste processo é a arte de transição - transiarte, que tem três componentes: I) a colaboração na produção da arte digital relacionada com o currículo; II) a motivação do estudante para produzir conhecimento a partir de sua própria identidade cultural; III) a profissionalização futura em tanto itinerário formativo desenvolvido no PROEJA-Transiarte.

A primeira etapa do Projeto PROEJA-TRANSIARTE financiada pela CAPES se deu no período 2007-1010. A segunda etapa teve inicio em março de 2013 e termina em 2016. Na primeira etapa, o PROEJA-Transiarte fez parte de um projeto de pesquisa do Programa de Apoio ao Ensino e à Pesquisa Científica e Tecnológica em Educação Profissional Integrada à Educação de Jovens e Adultos - PROEJA/CAPES/SETEC, Edital 03/2006, oriundo de um Acordo de Cooperação entre a Fundação Coordenação de Aperfeiçoamento de Pessoal de Nível Superior (CAPES) e a Secretaria de Educação Profissional e Tecnológica (SETEC) do Ministério da Educação. Na região centro-oeste, o projeto de número 19, "O PROEJA indicando a reconfiguração do campo da Educação de Jovens e Adultos com qualificação profissional - desafios e possibilidades" integrou uma rede de pesquisa formada pela UFG (Universidade Federal de Goiás), que coordenou as atividades; o Instituto Federal de Educação, Ciência e Tecnologia, com o subprojeto 1; a Universidade Católica de Goiás, com o subprojeto 2; e a Universidade de Brasília, com o subprojeto 3. O PROEJA-Transiarte constitui-se como Subprojeto 03, com o título de "Transiarte na Educação de Jovens e Adultos e na Educação Profissional - Proposta da Faculdade de Educação da Universidade de Brasília - UnBFE-Programa de Pós-Graduação em Educação". A pesquisa, que teve início em março de 2007, teve como local e contexto as escolas CEM03 (Centro de Ensino Médio 03) e ETC (Escola Técnica de Ceilândia).

Ceilândia foi criada oficialmente em 1989, mas desde 1971 foi local de assentamento das famílias de operários candangos que participaram da construção de Brasília. Ceilândia apresenta uma relevante diversidade cultural, concentrando um grande número de nordestinos. Existem movimentos que representam o artesanato, a literatura, o cinema popular, grupos musicais de rap, rock, forró, repente, e a orquestra sinfônica da cidade. O Centro de Ensino Médio 03 em Ceilândia atende a 3272 alunos, sendo 1139 do ensino regular e 2133 da EJA (Educação de Jovens e Adultos). 
Os alunos têm uma média de idade de 18 a 45 anos e residem em diferentes setores da cidade, sendo $60 \%$ mulheres. A ETC - Escola Técnica de Ceilândia foi inaugurada em 1982, oferece cursos de educação profissional nos níveis básico e técnico, com o objetivo de contribuir com a qualificação para o mercado de trabalho e desenvolvimento da população do Distrito Federal e entorno (RODRIGUES, 2010).

No ano de 2012 a pesquisa do Projeto PROEJA-Transiarte teve continuidade com parceria da Secretaria de Educação do Distrito Federal e o financiamento do projeto de pesquisa pela CAPES a partir de março de 2013. Desde então o grupo PROEJA-Transiarte integra a rede de pesquisa do programa Observatório da Educação - Edital 049/2012/CAPES/INEP com a Universidade Federal de Goiás e a Universidade Federal do Espírito Santo, denominado: Desafios da Educação de Jovens Adultos integrada à Educação Profissional: identidades dos sujeitos, currículo integrado, mundo do trabalho e ambientes/mídias virtuais, constituída com financiamento do Programa de Apoio ao Ensino e a Pesquisa Científica CAPES.

\section{REFERENCIAL TEÓRICO}

A percepção que nos entrega os dados empíricos do mundo em volta e dá origem às experimentações sensoriais estéticas são geradas num período histórico determinado e de acordo com suas características específicas (Benjamin, 1996). Hoje, nos situamos na chamada sociedade da informação ou do conhecimento, que entre outras características requer de seus cidadãos o desenvolvimento de "habilidades intelectivas" (ZUBOFF, 2004), isto é, habilidades que sejam conceituais e técnicas, para melhor funcionar na sociedade contemporânea. Todos os setores sociais são afetados pelas mudanças causadas pela tecnologia digital. Este impacto se faz sentir também na arte e na cultura, em particular na arte digital e ciberarte.

A ciberarte é vista assim em relação ao conceito da reprodutibilidade técnica da obra de arte (BENJAMIN, 1996) quando novas tecnologias se tornam artefatos utilizados nas novas formas de expressão artística. Ao mesmo tempo, a obra de arte perde seu valor aurático enquanto é acelerada uma maior democratização e massificação das experiências artísticas. Desta maneira as tecnologias digitais ampliam as possibilidades de expressividade do individuo através da ciberarte e outras formas de arte digital.

A transiarte é uma das formas da ciberarte que promove um elo entre o presente não virtual e o espaço/tempo interativo virtual. Essa dimensão de convergência entre as novas formas de arte com as formas mais tradicionais mostra um processo de reconfiguração do passado no presente. Esse processo de remodelação ou refashioning do algo existente ou fabricado é o que chamamos de "reconfiguração estética virtual", onde a produção artística com seus suportes e outros implementos da arte "tradicional" ou arte "anterior" são repensadas e reconfigurados, passando a expressar novas estéticas, agora digitais, que povoam o campo do ciberespaço. São, portanto, dimensões do existente que foram remodeladas com tecnologia digital, gerando novas expressões artísticas. (TELES, 2008).

Estas novas mídias só realmente puderam ser adotadas socialmente pelo que elas tinham de "velho":

os novos meios encontram sua relevância cultural quando reavaliam e revitalizam meios mais antigos, como a pintura perspectivada, o filme, a fotografia e a 
televisão. Na verdade, os chamados "novos meios" só puderam se impor como "novos" e ser rapidamente aceitos e incorporados socialmente pelo que eles tinham também de "velhos" e familiares. A esse processo de remodelação ou reajuste (refashioning) dos meios precedentes eles dão o nome de "remediation" (re-mediação). (MACHADO, 2007, p. 72-73)

A passagem do real físico-presencial para o real-virtual, ou seja, a digitalização de componentes artísticos produzidos por meio das técnicas das artes "tradicionais" permite capturar expressões artísticas agindo como uma linguagem norteadora do fazer artístico.

Na transiarte os artistas têm a liberdade de desenvolver suas criações utilizando a técnica com a qual eles tem mais familiaridade ou aptidão e o foco é no trabalho de grupo, muitas vezes em um formato remix (MACHADO, 2007) expressivo e utilizando mídias digitais apropriadas.

Os trabalhos são interativos e podem ser acessados, modificados e utilizados pelos usuários, fazendo da Web sua "galeria de arte." Ao subscrever os trabalhos gerados pela criação coletiva, é utilizado um modelo de autoria do domínio publico e do creative commons (www.creativecommons.com.br). Desta maneira a transiarte é compartilhada livremente.

$\mathrm{Na}$ sociedade contemporânea os indivíduos estão vivenciando uma reinvenção da identidade cultural (HALL, 2005). Esse processo se dá a partir de profundas mudanças, às quais os indivíduos e grupos buscam a adaptação nesta sociedade midiática, que requer de seus habitantes novos tipos de comunicação e criatividade. Ciberartistas participam através do ciberespaço e a navegação e interação facilitam também um processo de criação de uma identidade cultural própria.

O processo de reinvenção da identidade cultural de um grupo pode ser ampliado com o acesso e o desenvolvimento de habilidades na utilização de nova mídia, com subsequente apoio das escolas para que os estudantes possam desenvolver sua arte digital de rede. A transiarte parte da arte existente de cada indivíduo, o que ele/ela mais aprecia ou executa em tanto forma de expressão artística.

\section{O PROJETO PROEJA-TRANSIARTE}

Considerando e reconhecendo esses alunos como trabalhadores adotamos a nomenclatura (EJAT). Neste sentido o objetivo do projeto é trabalhar com educandos da Educação de Jovens e Adultos Trabalhadores (EJAT) na introdução de novas linguagens artísticas digitais no currículo da educação da EJA, como a ciberarte.

O movimento que deu início à ciberarte teve início nos anos 60, com o intuito de explorar formas expressivas com a tecnologia digital. Com o aparecimento da Internet e do ciberespaço, houve o desenvolvimento da Web arte (Nunes, 2010), ou ciberarte (Venturelli \& Teles, 2008).

Ainda nesta área de pesquisa e criatividade digital, existem trabalhos e pesquisas de Suzete Venturelli (2004), Priscila Arantes (2005), Arlindo Machado (2007), Lucia Leão (2003), Gilberto Prado (2010), Lucia Santaella (2009), Beatriz Medeiros (2005), entre outros. Todos exploram o conceito da estética digital em diferentes ambientes e ferramentas. Existem instalações e experimentos que apenas podem ser acessados em galerias de arte físicas, presenciais, ou galerias de trabalhos em ciberarte que são acessíveis no ciberespaço. 
Para Domingues (2004) a expressividade da ciberarte se encontra, sobretudo, no processo da comunicação humana:

A ciberarte é, pois, uma arte da comunicação, um evento dialógico que acontece apenas com a participação do espectador. "O paradigma da representação, a ideia do belo, a contemplação da imagem ou de um objeto é trocada pela ideia de um processo a ser vivido" (DOMINGUES, 2002. p. 63).

Existem várias categorias de ciberarte (Venturelli \& Teles, 2008). Aqui é discutida uma destas categorias, a da transiarte, ou arte de transição, que foi concebida como uma ponte entre a arte não digital e a arte digital colaborativa.

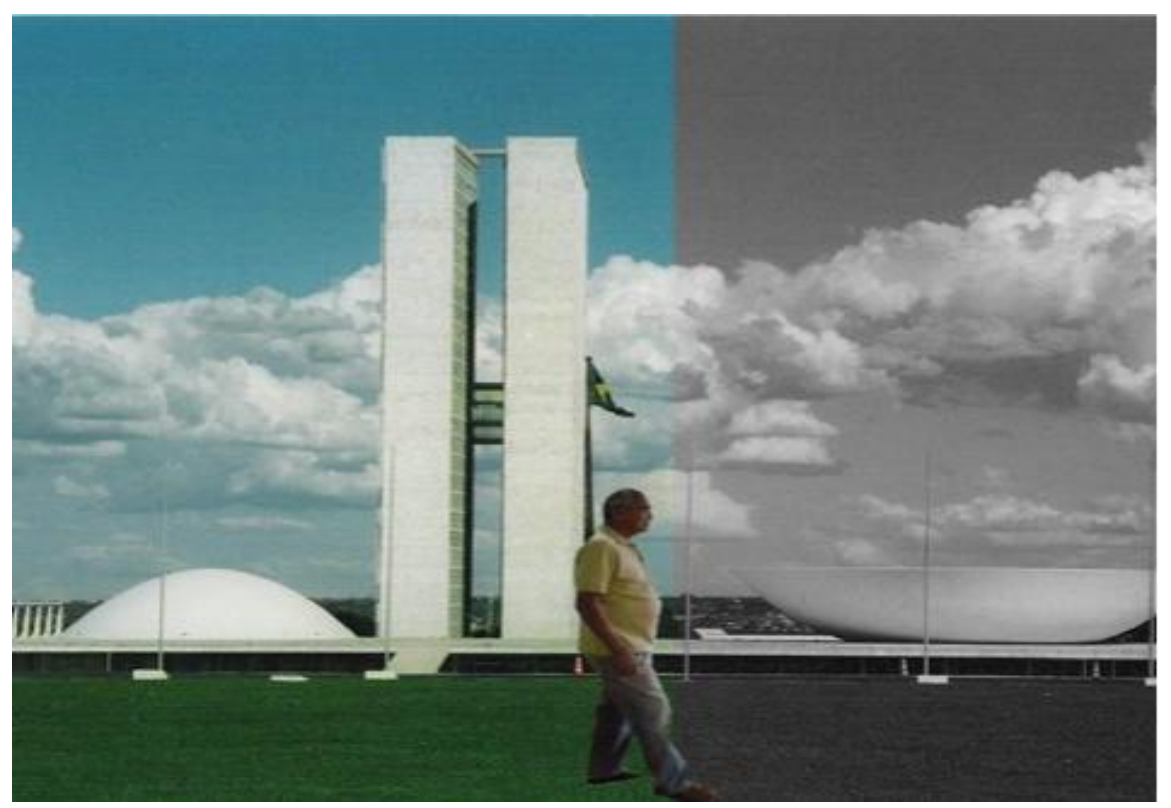

Figura 1: Tela de "Encontro de Gerações"

Na Figura 1 pode ser visto um exemplo de produção transiarte mostrando o momento no vídeo "Encontro de Gerações", do currículo de historia, onde é discutido o período JK. No vídeo o candango caminha pelas construções de que participou e ao fazê-lo o branco e preto da tela se torna colorido. Este estudante estava em um grupo de trabalho transiarte e narra a sua historia de vida mostrando como havia participado da construção de Brasília. 


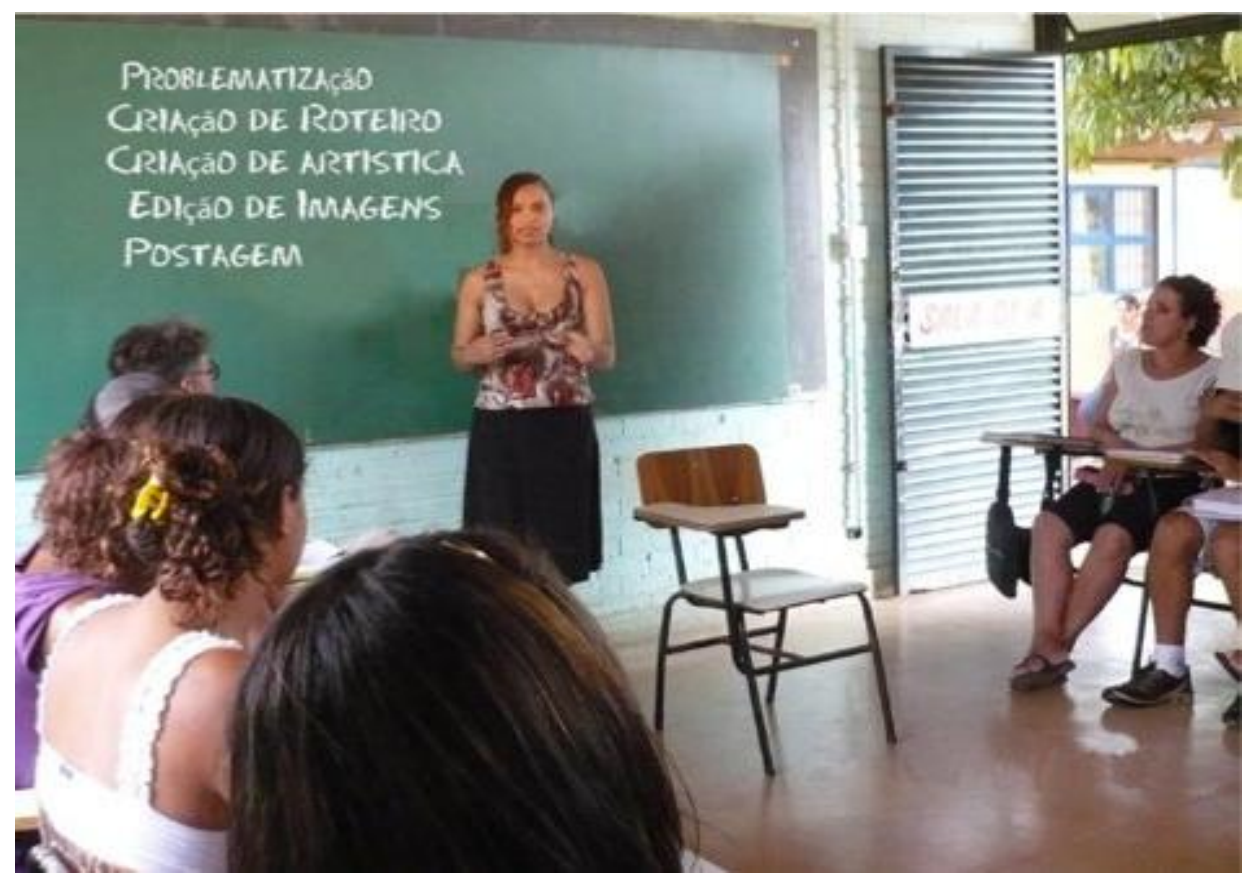

Figura 2: Grupo de trabalho transiarte

Este processo de mediar expressões artísticas entre o presencial e o virtual se dá por meio de uma atividade coletiva de repassamento de expressões artísticas existentes antes do digital para novas expressões estéticas reconfiguradas no ciberespaço (TELES, 2012).

Os participantes do Projeto de Pesquisa PROEJA-transiarte desenvolveram habilidades artísticas e técnicas neste processo que lhes permitiram uma participação ativa e criativa no Projeto.

O Projeto se propôs também explorar a relação do PROEJA com a transiarte na criação de um currículo que integrasse as mídias digitais e a experiência vivida e que, ao mesmo tempo iniciasse um itinerário formativo abrindo opções de profissionalização para os participantes. 0 itinerário formativo inclui o desenvolvimento de habilidades no uso de softwares de criação artística digital e postagem no ciberespaço.

O sistema educacional tem sido lento na adoção das novas tecnologias para o ensino/aprendizagem, para promover criatividade e produção artística, ainda que muitos estudantes já utilizem estas novas tecnologias no seu dia-a-dia para comunicação, acesso e produção de objetos artísticos digitais, como fotos, videoclipes, canções, simulações e jogos. Estas produções apresentam a estética da ciberarte, como a interatividade, a noção da produção coletiva, a reutilização de outros objetos digitais através de reconfigurações estéticas virtuais. 


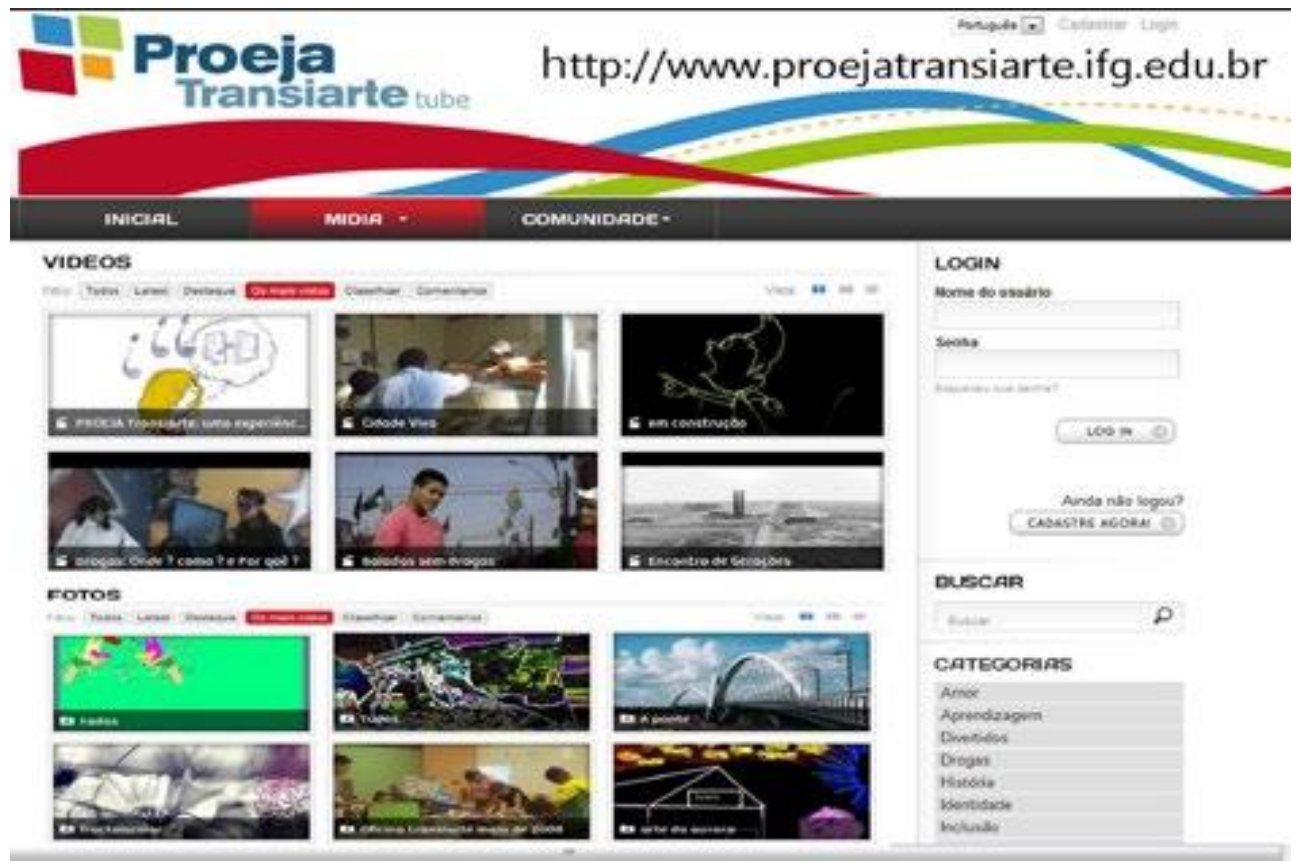

Figura 3 - 0 site do PROEJA-Transiarte

O projeto PROEJA-Transiarte que se leva cabo no CEM-03 e a Escola Técnica de Ceilândia em parceria com a UnB, teve inicio em 2007 com o objetivo de desenvolver uma forma de ciberarte, a transiarte, junto a estudantes EJA do segundo e terceiro segmentos, como forma de produção artística colaborativa, de inclusão digital e curricular, quando participantes desenvolveram também uma identidade cultural comum no processo colaborativo de produção da arte digital. O projeto se realiza em tanto pesquisa colaborativa utilizando a pesquisa-ação como norteadora do projeto.

\section{APRENDIZAGEM COLABORATIVA NO PROEJA-TRANSIARTE}

A aprendizagem colaborativa se dá nos moldes da ajuda entre membros do mesmo grupo. A diversidade de habilidades entre membros de um grupo tende a ser significante, cada um podendo compartilhar aquilo que faz ou deseja expressar. Aqueles mais capazes em áreas especificas do trabalho do grupo ajudam colegas a desenvolverem estas novas habilidades (Vygotsky, 1991).

A colaboração no processo de criação artística teve início com os trabalhos coletivos em teatro nos anos 60 (ABREU, 2004; CUNHA, 2007). A colaboração artística no ciberespaço é uma atividade estética mais recente. Dado o caráter aberto da rede Web, o compartilhamento de informações e trabalho é uma atividade frequente no ciberespaço. 0 processo de colaboração e produção artística na transiarte inclui dez passos:

I. Contato com o educador e discussão com os educandos sobre a proposta do projeto;

II. Uma vez estabelecida a participação formam-se grupos de trabalho não muito grandes, com o máximo de oito participantes e dá-se início à discussão sobre a transiarte;

III. Início da discussão sobre qual será o tema do trabalho artístico; 
IV. Formato de apresentação do tema: fotos, músicas, animações, vídeos, teatros, entre outros, são opções a serem exploradas, todas elas para serem postadas na Web;

V. Planejamento e design do trabalho;

VI. Elaboração de um roteiro;

VII. Execução artística (colagens, desenhos, pinturas, massinha, bonecos, teatro e outros mais). Utilização de luz, cores, harmonia, textura, proporção, interação na transiarte;

VIII. Execução técnica pré-digital (técnicas artísticas digitais e audiovisual, como fotografias, filmagens, gravação de entrevistas, depoimentos, sons e músicas);

IX. Execução e montagem digital (uso de site de busca de vídeos, músicas, imagens, programas para edição de imagens e vídeos como Gimp, PhotoShop, Photo Paint, MovieMaker, AdobePremiere);

X. Postagem no site www.proejatransiarte.ifg.edu.br

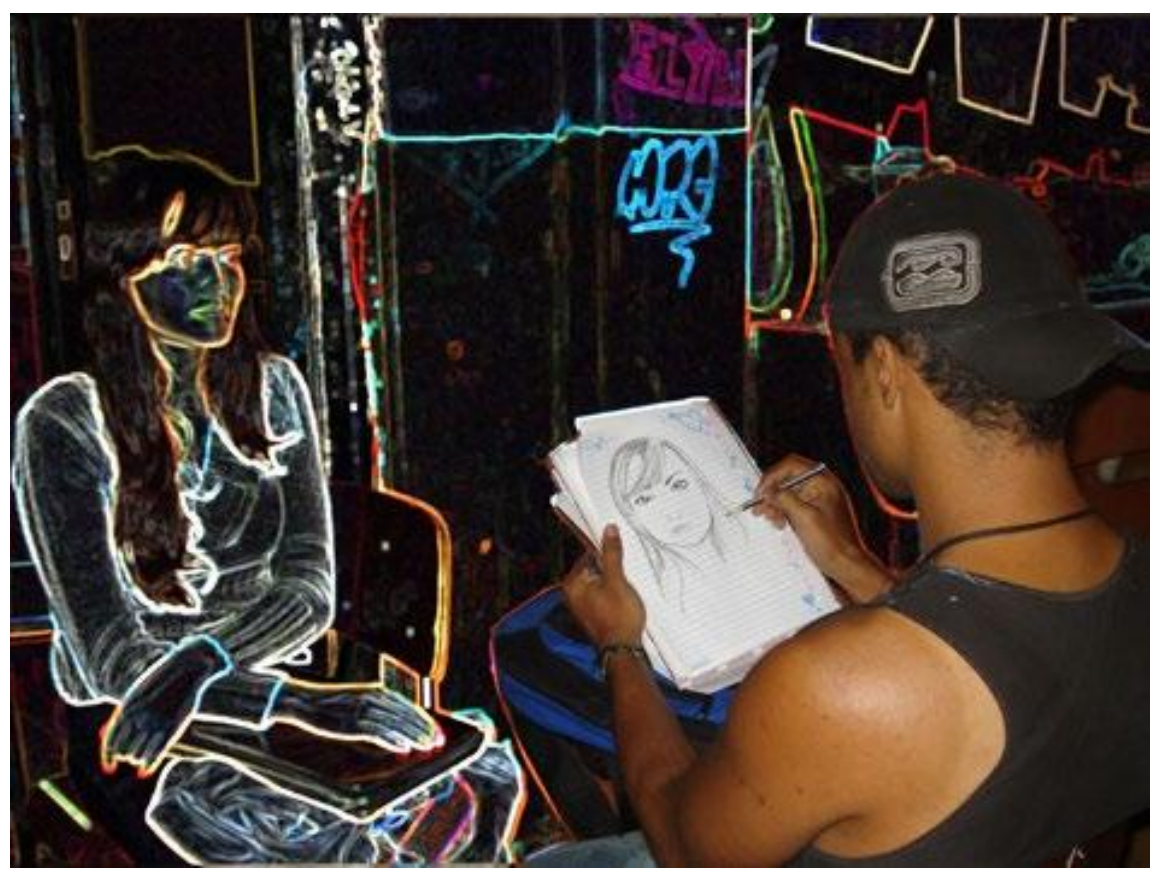

Figura 4: Produção da transiarte

O trabalho coletivo na transiarte implica na construção artística de caráter autoral coletivo, uma obra aberta que pode ser copiada, modificada e transmitida no ciberespaço. Neste processo de criação os autores ou os interatores têm, dentro da ciberarte, infinitas possibilidades de expandir a criatividade.

Assim, como já havia observado Benjamin (1996), a diferença entre autor e publico tende a desaparecer: "a diferença essencial entre autor e público está a ponto de desaparecer. Ela se transforma numa diferença funcional e contingente". Ainda que a frase de Benjamin tenha sido escrita no século passado e se refira somente a mídias como a imprensa, o cinema, e a fotografia, esta tendência histórica da eliminação progressiva da distinção entre autor e público parece se 
reforçar ainda mais na era digital. A arte deixa de ser o privilégio de poucos, assim como deixa de ser cada vez mais apenas o observável mas também o vivenciado.

\section{METODOLOGIA DE PESQUISA}

A metodologia utilizada no projeto de pesquisa PROEJA-Transiarte é a pesquisa- ação (Barbier, 2004). A pesquisa-ação no PROEJA-Transiarte é uma construção coletiva de conhecimento, que trabalha não só com a palavra, mas com a imagem. Segundo Angelim et al (2012):

Ação sem reflexão se converte em ativismo. Esse é um dos cuidados da pesquisaação de sujeitos implicados, isto é, envolvidos como grupo, na transformação da realidade escolar considerada como um organismo vivo, como uma teia, uma rede de tramas e tensões, situada em um campo interinstitucional, onde confluem culturas e relações de poder que resultam da história do Distrito Federal, e da cidade de Ceilândia.

A metodologia da pesquisa-ação permite a modificação da realidade em conjunto com os participantes. Busca facilitar a aprendizagem colaborativa de educandos do PROEJA a partir da inclusão digital e social destes, seja pela utilização de softwares de criação e edição audiovisual, ou mesmo a participação ativa em redes sociais de forma crítica e criativa.

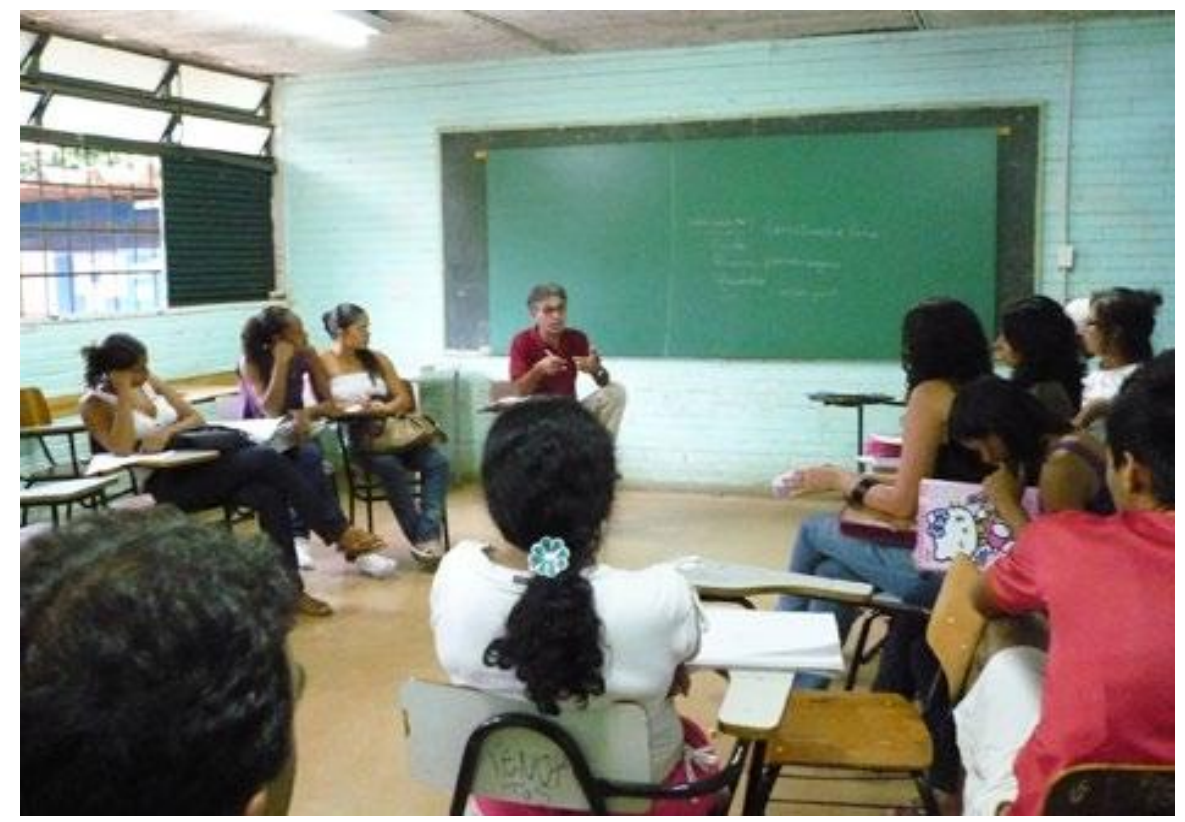

Figura 5: Professor de historia discute projeto transiarte com alunos

A pesquisa-ação rompe com a tradição cartesiana de pesquisa que propõe o isolamento do pesquisador do objeto pesquisado e propõe o oposto: o pesquisador deve se envolver com o objeto pesquisado. Por isso a pesquisa-ação propõe probabilidades como possíveis resultados, mas probabilidades de ação. As probabilidades enunciadas no inicio do projeto são discutidas por Angelim et al (2012, p.59) abaixo. São elas: 
Probabilidade 1: O Proeja Transiarte como uma nova linguagem incluída no espaço curricular. Uma linguagem que se constitui não pela tradição escolar da primazia da palavra escrita, mas que é composta de sons, de cores, de imagens, da palavra falada e escrita, e animações. Elaboramos esta probabilidade a partir da experiência de construção/produção de videoclipes por professores e estudantes de diferentes turmas e disciplinas, junto com estudantes e professores da UnB. A linguagem, portanto, foi confirmada na pesquisa como nova linguagem de aprendizagem. Estudantes participantes do projeto tiveram também uma taxa de evasão inferior que aqueles que não participaram. Assim que se pode pensar esta probabilidade da inclusão desta nova linguagem no currículo escolar como uma nova linguagem.

Probabilidade 2: 0 Proeja Transiarte como um módulo inserido em outros cursos de formação profissional já existentes, como o de web design, por exemplo. $O$ alicerce desta probabilidade foi a constituição de um curso intitulado Ciberarte 1, ofertado na Escola Técnica de Ceilândia. Esta é uma probabilidade que, levada à execução mais completa, pressupõe a formação de professores de EJA em Transiarte, a formação de multiplicadores em transiarte. Seguimos questionando-nos sobre o alcance, sobre a formulação adequada de nossas probabilidades. Perguntamo-nos, por exemplo, se os estudantes idosos de EJA poderiam formar-se nas habilidades digitais a ponto de profissionalizarem-se nessa área, indicando um itinerário formativo. Ou se a curiosidade e a atração que o computador desperta em jovens e adultos chegariam a uma configuração profissional (quer na probabilidade 2, como na 3). Ponderamos sobre a estruturação coletiva do itinerário formativo, sobre se o currículo de EJA + EP não seria, sob o ponto de vista do cooperativismo, uma ação individual, um diploma para ser colocado no mercado. Perguntamonos: E quanto a um processo formativo que levasse a uma produção na forma de cooperativa? Uma autogestão cooperativa nesse tipo de serviço? Estas são indagações muito recentes no grupo, que nos levarão a outras questões, até que algumas afirmações se concretizem.

Probabilidade 3: O Proeja Transiarte como uma nova ocupação profissional, ou um novo perfil formativo que faça parte do Catálogo Brasileiro de Ocupações (CBO). As perguntas são muitas. Algumas encerram afirmações: o que os estudantes estão aprendendo que poderia levar o referencial e fundamentos da transiarte ao $\mathrm{CBO}$ ? Estética e design de interfaces, a interestética (ARANTES, 2005)? Quem empregará os estudantes formados nesses cursos? Para isso, já é possível entrever uma resposta: algumas instituições públicas poderão fazê-lo, em seus programas de responsabilidade social. O conhecimento do uso de softwares livres e comerciais de suporte ao design digital como Audacity, GIMP e outros é necessário para esta nova profissão, que combina arte e design com conhecimentos técnicos.

Essas são probabilidades, mas são também ponderações. São reflexões sobre nossa ação que e que povoam nosso universo cognitivo, nos momentos em que nos reunimos para afirmarmos o que estamos fazendo, o que podemos e devemos fazer, ou aquilo que devemos evitar. Um de nossos papéis de pesquisadores seria, então, junto com a "escola profissional", consultar o Catalogo Brasileiro de Ocupações - CBO e analisar quais as profissões mais próximas da estética da transiarte. Propor um programa para os estudantes mais voltado para a transiarte, encarando a arte como outra forma de cognição. Nesse programa, formaríamos um perfil a partir do que o estudante já conhece, e não um programa constituído a priori. O sentido do Proeja é que o ensino médio em EJA tenha, necessariamente, uma ligação com a educação profissional. 


\section{CONSIDERAÇÕES QUASE FINAIS}

Depois de quatro anos do Projeto PROEJA-Transiarte, no período 2007-2010, podemos afirmar que das três probabilidades discutidas anteriormente, tanto a primeira como a segunda foram confirmadas e estão sendo implementadas. A inclusão da transiarte como nova linguagem na escola se revelou como um fator positivo na aprendizagem, gerando motivação e interesse dos estudantes. Um curso de Formação Inicial Continuada - FIC, e um curso de Design de multimeios para Web estão sendo desenvolvidos, aplicando o conceito de transiarte no design dos mesmos. Também um curso online de introdução à transiarte está sendo elaborado para a formação de professores neste modelo de ensino lúdico e integrado com o proeja.

Como o projeto de pesquisa foi financiado pela CAPES por outros quatro anos, com inicio em 2013, vemos agora uma oportunidade para aprofundar nossa exploração da transiarte nas probabilidades 1 e 2 e assim institucionalizar em várias escolas uma prática de transiarte como uma nova linguagem na escola assim como a formação de professores nesta área. Esperamos que este material possa servir de referência ao uso de TICs no proeja e contribuir para o fortalecimento da Educação de Jovens e Adultos Trabalhadores.

\section{REFERÊNCIAS BIBLIOGRÁFICAS}

1. ABREU, Luís Alberto. (s/d). Processo Colaborativo: Relato e Reflexões sobre uma Experiência de Criação, em <http://www.sesipr.org.br/nucleodedramaturgia/FreeComponent9545content77392.shtml>.

2. ANGELIM, M.L.P. (2008). Pedagogia de la liberación. In: Diccionario Latinoamericano de Bioética. Dir. Juan Carlos Tealdi. Bogotá: UNESCO. Red Latinoamericana y del Caribe de Bioética: Universidade Nacional de Colômbia.

3. REIS, Hilário; Bruzzi,Rita.(2012).A Pesquisa-Ação no PROEJA-Transiarte. In: REIS, Renato Hilário; CASTIONI, Remi; TELES, Lúcio França.(orgs). Proeja-transiarte: construindo novos sentidos para a educação de jovens e adultos trabalhadores. Brasília: Verbena,p.78-93.

4. ARANTES, P. (2005). Arte e mídia: perspectivas da estética digital. São Paulo: Editora SENAC.

5. BARBIER, René. (2002). A pesquisa-ação. Tradução de Lucie Didio. Brasília: Liber Livro.

6. BENJAMIN, Walter (1996). A obra de arte na era de sua reprodutibilidade técnica. In: BENJAMIN, W. (1996). Magia e Técnica, Arte e Política. São Paulo: Editora Brasiliense.

7. CASTIONI, Remi. Educação e inserção ocupacional no Distrito Federal e na Região Administrativa de Ceilândia: Lócus do PROEJA-Transiarte. In: Teles, Lucio, Castioni, Remi, Reis, Hilários (orgs). (2012) PROEJA-Transiarte: Construindo Novos Sentidos para a Educação de Jovens e Adultos Trabalhadores: Brasília, Editora Verbena.

8. CUNHA, Ana (2007). Arte colaborativa e cibercultura: A visão dos coletivos Superflex e De geuzen a respeito da linguagem digital. Disponível em: <http://cencib.org/simposioabciber/PDFs/CAD/Ana\%20da\%20Cunha.pdf>. Acessado em: 08/01/20012.

9. DOMINGUES, D. (2002). Criação e interatividade na ciberarte. São Paulo: Editora Experimento.

10. LEÃO, Lucia, (organizadora). (2003). O Chip e o Caleidoscópio - Reflexões sobre as novas 
mídias. São Paulo: Editora SENAC.

11. LEMES, Julieta Borges. (2012). O Proeja Transiarte na EJA do Centro de Ensino Médio 03 e na Educação Profissional do Centro de Educação Profissional de Ceilândia: significações e indicações de estudantes à elaboração de um itinerário formativo. (Dissertação), FE-UnB.

12. LIESEN, M. (2005). Navegando na ciberarte: notas sobre arte e imaginário na contemporaneidade. Revista Eletrônica de Ciências Sociais, n. 8 - Março de 2005, p. 71-94.

13. MACHADO, A. (2007). Arte e mídia. Rio de Janeiro: Zahar Editor.

14. MARCO, Kátia. (2004). A diluição do autor na ciberarte. Disponível em: <www.gestaocultural.org.br/pdf/autornaciberarte-katia.pdf $>$, acessado em 18/05/2012>.

15. MEDEIROS, Maria Beatriz. (2005). Aisthesis: Estética, Educação e Comunidades.Chapecó, SC: Editora Argos.

16. MOLES, Abraham. (1990). Arte e Computador. Porto: Afrontamento.

17. PRADO, Gilberto. (2010). Redes e ambientes virtuais artísticos. In: FELICE, Massimo Di; PIREDDU, Mario. (Org.). Pós-Humanismo: as relações entre o humano e a técnica na época das redes. 1a ed. São Caetano do Sul: Editora Difusão, v. 2, p. 285-301.

18. REIS, Renato Hilário; CASTIONI, Remi; TELES, Lúcio França.(orgs).(2012). Proeja-transiarte: construindo novos sentidos para a educação de jovens e adultos trabalhadores. Brasília: Verbena.

19. RODRIGUES, Dorisdei. (2010). Projeto PROEJA-Transiarte: uma experiência de pesquisa ação em ciberarte. Dissertação de Mestrado, FE-UnB.

20. SANTAELLA, Lucia. (2008).Navegar no ciberespaço. São Paulo: Editora Paulus. SANTAELLA, Lucia \& ARANTES, Priscila. (2008). (Org.). Estéticas Tecnológicas: Novos Modos de Sentir. São Paulo: Editora PUC-SP.

21. TELES, L.; ZIM, A. (2011). A criação de identidade cultural de grupo na produção de ciberarte. In: 10th Encontro Internacional de Arte e Tecnologia. Brasília.

22. TELES, L.; VENTURELLI, S.(2008). Introdução à Arte Digital. Brasília: Creative Commons Brasil. Disponível em: <http://www.fe.unb.br/quem-e-quem/docentes/l/lucioteles/mi- nhaspublicacoes/artedigital.pdf/view>, acessado em 18/05/2012.

23. TELES, Lucio. (2008). Reconfigurações estéticas virtuais na transiarte. In: MARTINS, R. (Org.). Visualidade e Educação. Goiânia: Editora Universidade Federal de Goiás.

24. THIOLLENT, Michel. (1985). Metodologia da pesquisa-ação. SP: Cortez.

25. VENTURELLI, S. (2004). Arte espaço - tempo - imagem. Brasília: Editora da Universidade de Brasília.

26. VYGOTSKY, L. S A formação social da mente, (1991). São Paulo: Fontes Editora Ltda.

27. ZUBOFF, Soshana (1984) In the Age of the Smart Machine. New York: Basic Books. 